\title{
Techniques for Production Quality Control in the Global Company
}

\author{
Naqib Daneshjo ${ }^{1 *}$, Peter Malega ${ }^{2}$, Peter Drábik ${ }^{1}$ \\ 1 Faculty of Commerce, University of Economics in Bratislava, Dolnozemska cesta 1, 85235 Bratislava Slovakia \\ 2 Faculty of Mechanical Engineering, Technical University of Kosice, Park Komenského 9, 04200 Kosice, Slovakia \\ * Corresponding author's email: daneshjo47@gmail.com
}

\begin{abstract}
In this article, the production quality control in the global company that works on the principle of World Class Manufacturing was described. The occurrence of a human error can be caused by a misunderstanding of the procedure, disregard of the instruction manual, and lack of organization in the workplace as well as lack of product or process understanding. Quality control is a wide-used managerial tool for carrying out tasks in order to provide continuity, avoid negative adjustments and retain the current state. Quality monitoring can be performed through three classic managerial procedures and it can be said that quality control is the best tool in today's environment.
\end{abstract}

Keywords: quality, quality control, quality maintenance, quality tools, 4M (machine, material, method, manpower)

\section{INTRODUCTION}

Optimization of production processes is characterized as the search of solutions the application of which eliminates the causes of decreased production efficiency. Process optimization should be the one of main components of business strategy that delivers benefits not only for customers, but also helps to increase the performance of production processes as well as the entire business. The basic approaches for production process optimization are continuous changes and progressive improvement. One of the optimization tools to facilitate planning is the Tecnomatix software, which was used in this paper to optimize the production system. The aim of the sixth pillar of methodology WCM (World Class Manufacturing) is the production of even smaller number of defects in all produced products with an effort to achieve zero errors [9]. In order to overcome the customers' expectations, it is very important to involve all employees. The purpose of this pillar is also increasing awareness of the quality importance in all activities and creating the products that are representative on the market $[1,20]$.
Quality includes not only the final assessment of the final product, but also the whole production process. A little doubt at any stage or a moment of inattention can cause defects in the product and have an impact on production [6].

During the Middle Ages and up to the nineteenth century the development of goods and services was limited mainly to a single individual or a small community. These entities were also family-owned firms, so the quality controlling of a product or service rested with that entity or small group - those who are often responsible for manufacturing the goods that comply with those requirements.

A second phase, called the foreman quality control era, emerged in 1900 and continued to about 1920. The idea of mass production, which was based on the theory of specialization of labour, came with the Industrial Revolution. An individual was liable not for the output of a whole product, but for only a part of it.

The period between 1920 and 1940 was the next step in the development of quality control. It was named the period of control of inspection quality. Products and processes have become more complex and the volume of production has 
increased. As the number of employees reporting to a foreman increased, it became very hard for the foreman to maintain close oversight of individual activities. Therefore, inspectors were designated after certain operations to check the quality of a product. Standards were set and the quality of the product produced was compared with those standards by inspectors. Between 1940 and 1960, the next stage in the evolution process, called by Feigenbaum the statistical quality control phase, occurred. In this stage, between the years 1938 and 1945, the production requirements escalated [4].

During the 1960s, the phase called complete quality control began. The gradual involvement of many divisions and managerial staff in the quality control process was a significant characteristic during this period. Most of these tasks were historically performed by individuals on the shop floor, by the manufacturing foreman, or by staff from the inspection and quality control department.

At the beginning of the 1970s came the large phase of the complete quality control organization, which brought the involvement of everybody in the company, from the operator, through managers on each line, to the general director. In this phase, quality was connected with every person in the company.

In the 1980s, the advertising campaigns in the United States of America put quality control on the top place. There was a lot of advertising related to the product quality and regular comparisons were made with those of rivals. These advertising campaigns aimed to point out some aspects of the product which were better to those of comparable products. The knowledge about the importance of quality has started to grow at all levels within the industry. An explosion of quality management software systems came on the market as computer use increased during the 1980s.

From the 1990s until now, a massive development of the information technologies occurred on each level of industries, so we can mark this stage as the information technology era. This is the greatest development since the late 18th century and the Industrial Revolution. The current century is characterized by using wireless technologies and it is also called the era of the digital revolution in information technology. These innovations encourage the preservation and security of the standard of information while giving data in an efficient way.
Different researchers have defined the term "quality" in various ways. The concept of quality is divided into five categories by Garvin, from transcendent, through product-based, user-based, and production-based, up to value-based. In addition, a system of eight attributes that can be used to describe quality was identified: performance, characteristics, reliability, conformity, longevity, serviceability, aesthetics, and perceived quality.

Crosby is the author of this most cited definition: "Quality meets requirements or specifications" [2]. Juran suggested a more universal definition: "Value is fitness for use" [7]. Mitra describes quality control as a system that holds the required level of quality through customer recommendations on product characteristics and corrective actions, if it is necessary [10].

\section{Quality control pillar}

The quality Control pillar emphasizes the application of the quality principles to all tasks of processes in the daily routine. For the purposes of quality problems prioritization, the matrix of quality assurance is used, which contains the information obtained from the disposal of the lines of customers, market, internal rejects and product repairs [22]. This matrix of quality is aimed at a comprehensive process with the aim to find the most serious defects with the highest priority. After their identification, it is necessary to apply quality tools to better understand and characterization of the problem in the details using $5 \mathrm{~W} 1 \mathrm{H}$ and to identify the potential causes of the problem. They are associated with the data from the analysis of 4M (machine, material, method, manpower), regarded as the main factors affecting the product quality.

Both quality tools are the basis for the identification of the defects and errors. For the determination of the main cause of the problem, definition of the activities, problem elimination and achievement of the zero defects, it is necessary to use other tools. WCM program proposes the tools to verify the factors and assess human errors, which may lead to their occurrence. This can be achieved through "Analysis of the main cause of human error" $[5,19]$.

In some cases, errors can cause unhealthy lifestyle habits that lead to mental and physical fatigue, lack of sleep or inadequate nutrition. In order to ensure quality and reduce the incidence of human errors, the Poka Yoke system can be 
used, which prevents operation execution, if components are missing or incorrect. It is easy to avoid errors using colours, symbols and illustrations, which makes it easier to understand the information [21].

Seven steps of quality maintenance are $[10$, 12, 15]:

1. Find current conditions.

2. Restore the original conditions.

3. Analyse the unknown causes.

4. Reduce and eliminate all potential causes.

5. Create conditions for zero errors.

6. Maintain the conditions for zero errors.

7. Improve the conditions for zero errors.

The PDCA cycle is helpful in achieving the required quality. It is necessary to draw up a plan ( $\mathrm{P}-\mathrm{Plan})$, execute it (D - DO), check the results (C - CHECK) and perform activities to continuously improve the process performance (A ACT), establish standards or documentation of the accepted measures. This enables to obtain greater visibility for the standards definition, which is a necessity for quality assurance in the production process. Application of the PDCA cycle is linked with the aim of achieving zero-defects [11].

\section{Quality control as a procedure}

Seven steps of quality control in Figure 1 provide a systemic, logical and detailed approach to rectifying the quality defects of $4 \mathrm{M}$ categories, see Figure $2[13,14]$ :

- Man.

- Method.

- Machine.

- Material.

Figure 3 illustrates the route map of quality control

\section{Quality maintenance}

The first step of quality maintenance is to assess the current conditions. It provides clarification of the relationship between the quality characteristics, equipment and production methods. In order to achieve positive results, it is necessary to create a team with the right skills and experience to fix the problem. This involves practical experience and technical knowledge. The basic tools in this step include process FMEA (Failure Mode and Effect Analysis) and QA matrix. QA matrix summarizes the problems according to the

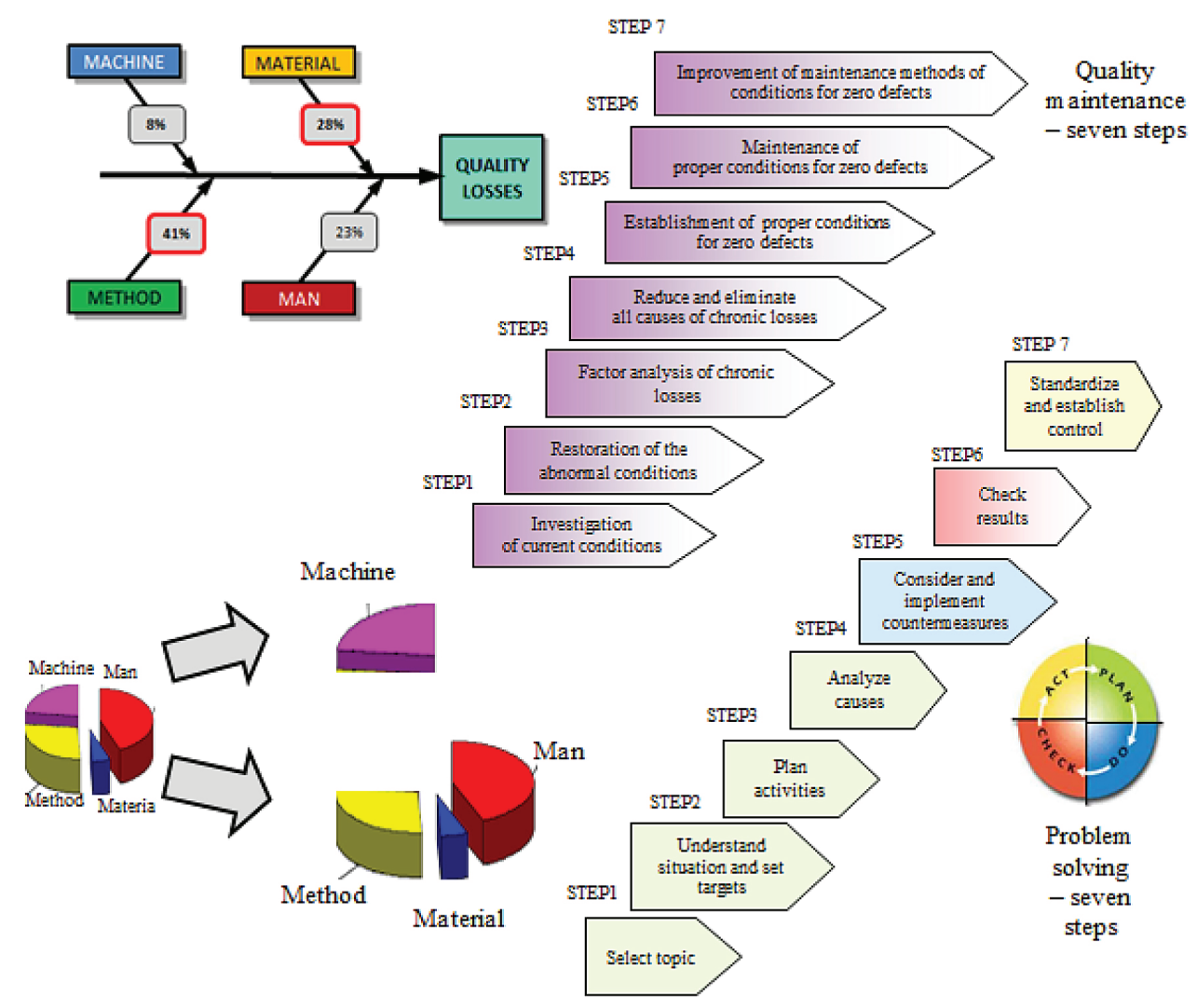

Fig. 1. Seven steps of control, problem-solving and quality maintenance 


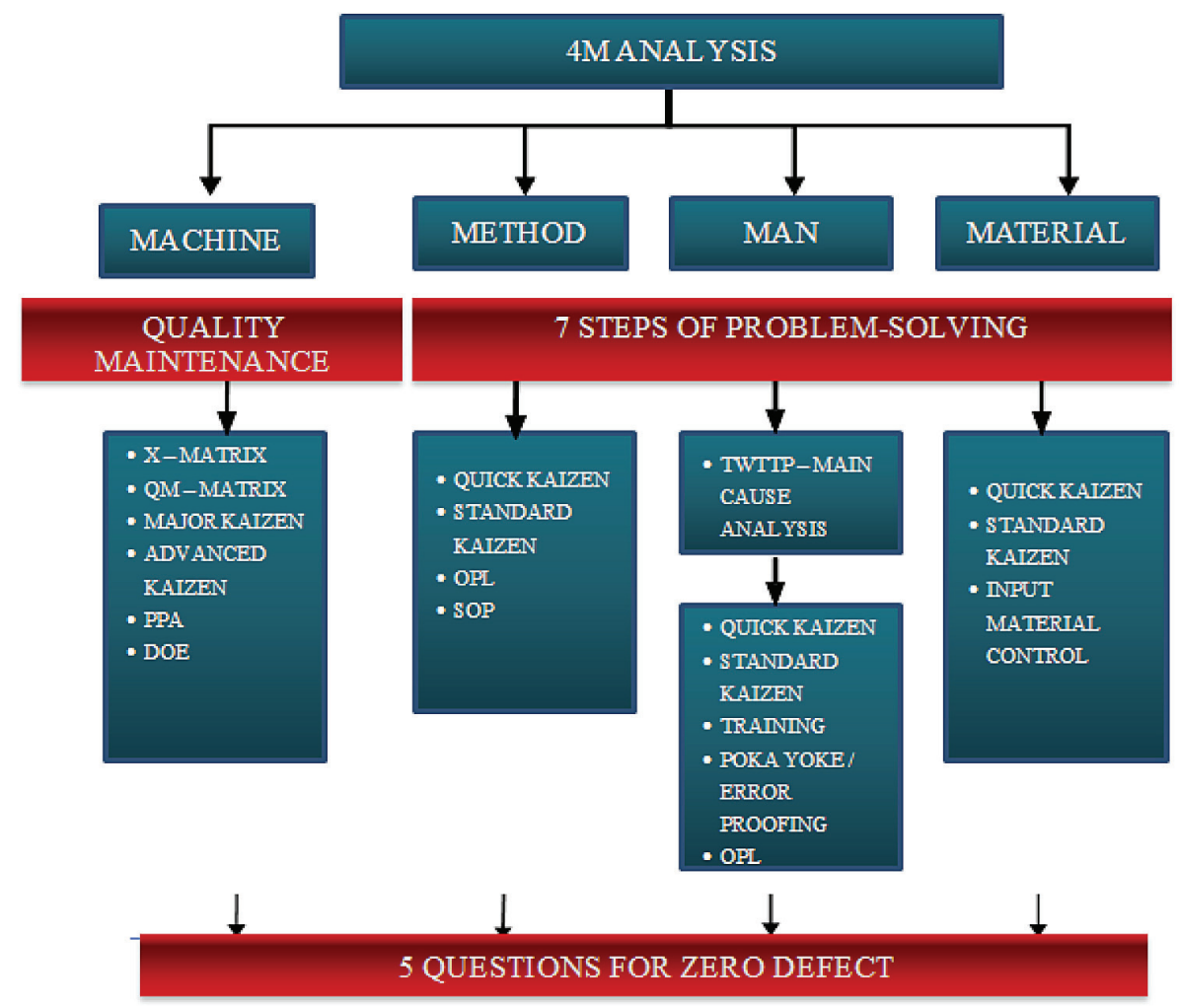

Fig. 2. Methodologies and used tools of quality within $4 \mathrm{M}$ analysis

\begin{tabular}{|c|c|c|c|c|c|}
\hline SCORE & 1 & 2 & 3 & $>4$ & 5 \\
\hline LOGIC & $\begin{array}{l}\text { Creation of basic } \\
\text { Knowiedge Defect } \\
\text { identification and } \\
\text { classification }\end{array}$ & $\begin{array}{l}\text { The process of } Q \\
\text { components determination } \\
\text { have been completed. }\end{array}$ & \begin{tabular}{|l} 
Application of \\
intermediate methods \\
and tools
\end{tabular} & 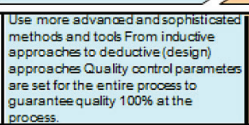 & \\
\hline $\begin{array}{l}\text { METHODOLOGY } \\
\text { DEVELOPMENT } \\
\text { IIMPROVEMENT }\end{array}$ & 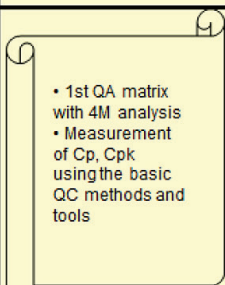 & 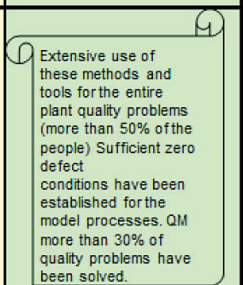 & 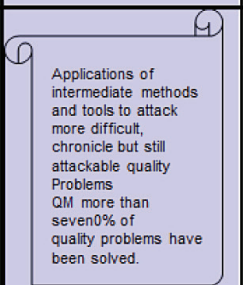 & 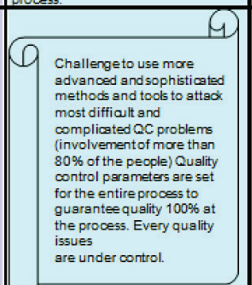 & $\begin{array}{l}\text { - Well } \\
\text { established } \\
\text { quality control } \\
\text { - Feedback } \\
\text { system to } \\
\text { EPM and } \\
\text { EEM }\end{array}$ \\
\hline & Miseven QCseven & Miseven QCseven & QCseven & QMiseve QCsevenm & Lseven QCseven \\
\hline & QM6 $L 6$ QC6 & QM6 L6 QC6 L6 & QMe L6 QC6 L6, & ${ }_{1 P} Q M 6 \quad L 6$ QC6 L6 AA & QM6 L6 QC6 L6 \\
\hline$>$ EXTENSION & QM5 $L 5$ QC5 $L 5$ & QM5 L5 QC5 L5 & QP QM5 L5 QC5 & A QM5 L5 QC5 L5 & QM5 L5 QC5 L5 \\
\hline & PQM4 L4 QC4 L4 & QM4 L4 QC4 L4 & A QM4 L4 QC4 & AQM4 L4 QC4 L4 & QM4 L4 QC4 L4 \\
\hline & QM3 L3 QC3 L3 & QM3 L3 QC3 L3 & QM3 L3 QC3 L3 & QM3 L3 QC3 L3 & QM3 L3 QC3 L3 \\
\hline & QM2 L2 QC2 L2 & QM2 L2 QC2 L2 & QM2 L2 QC2 L2 & QM2 L2 QC2 L2 & QM2 L2 QC2 L2 \\
\hline & QM1 L1 QC1 L1 & QM1 L1 QC1 L1 & QM1 L1 QC1 L1 & QM1 L1 QC1 L1 & QM1 L1 QC1 L1 \\
\hline
\end{tabular}

Fig. 3. Route map of quality control

impact in first level WCM indicators. Through criteria standardization, the QA matrix provide the directions to problems prioritization [16].

Stratification of the problem determines the line, equipment or machine that causes the greatest losses. The most important basic tool for the investigation of current conditions is $5 \mathrm{G}$ (Gemba, Gembutsu, Genjitsu, Genri, Gensoku) observations that must be done on the place of the problem. As part of conditions assessment, it includes the macro view of the machine with its parts and each activity. The result of examination using the $5 \mathrm{G}$ tools in $5 \mathrm{~W} 1 \mathrm{H}$ (5 Why + 1 How) determines description of the revised problem, which is the sum of all the controlled conditions. 
The second step of the quality maintenance is restoring the basic conditions. It includes the restoration of a device into a perfect condition. The investigation is carried out by using the $4 \mathrm{M}$ conditions with the table of countermeasures against defects. This step is crucial [8, 17]. Restoring using autonomous and preventive maintenance has to be carried out carefully to make it clear whether or not it is necessary to prepare PPA (Processing Point Analysis). If the second step is not elaborated with absolute precision, there is a risk that costly and time consuming process of analysis preparation may develop, when in fact it is sufficient only to restore the basic machine's conditions $[3,18]$.

In this step the important process parameters are defined and also the parameters checked. Checklist is an appropriate tool, which is used to control the specified parameters. Checklist should include [13]:

- Description of the parameter.

- Nominal value.

- Current value.

- Analysis of results.

- Importance of parameter.

The sequence of steps for checking and restoring the basic conditions is shown in Figure 4.

If a company achieves zero disposals after returning to the basic conditions, which is the aim of the project, then it continues to step 5 of quality maintenance. If zero disposals were not achieved after returning to the basic conditions, it is necessary to open PPA analysis and continue with 7 steps of PPA analysis. Already in the third step, it is important to invite other pillar-focused improvement due to the necessity of preparing advanced tool of PPA.

Seven steps of the PPA analysis (Figure 5) are aimed at approximation of the greatest problems on machines that have a connection with the hidden main causes. This analysis gets process under control.

X-Matrix (Figure 6) is used to display details and subsequently the control of relationship between defects and phenomenon. It shows the interconnection between defect, phenomenon component/machine part and characteristics of the component.

The QM matrix (Table 1) is used to maintain the conditions that are necessary to achieve zero defects and constitutes a summary of steps three, four and five. It defines a way of control and control frequency of process parameters.

Solving the problem is concluded with five questions for the zero machine defects, which at least $80 \%$ of activities must be achievement (Table 2).

\section{Quality tools}

All results can be recorded through basic quality tools, while the most commonly used tools are:
a) Ishikawa diagram.
b) Checklist.
c) Quality control chart.
d) Histogram.
e) Pareto chart.
f) Scatter plot.
g) Flowchart.

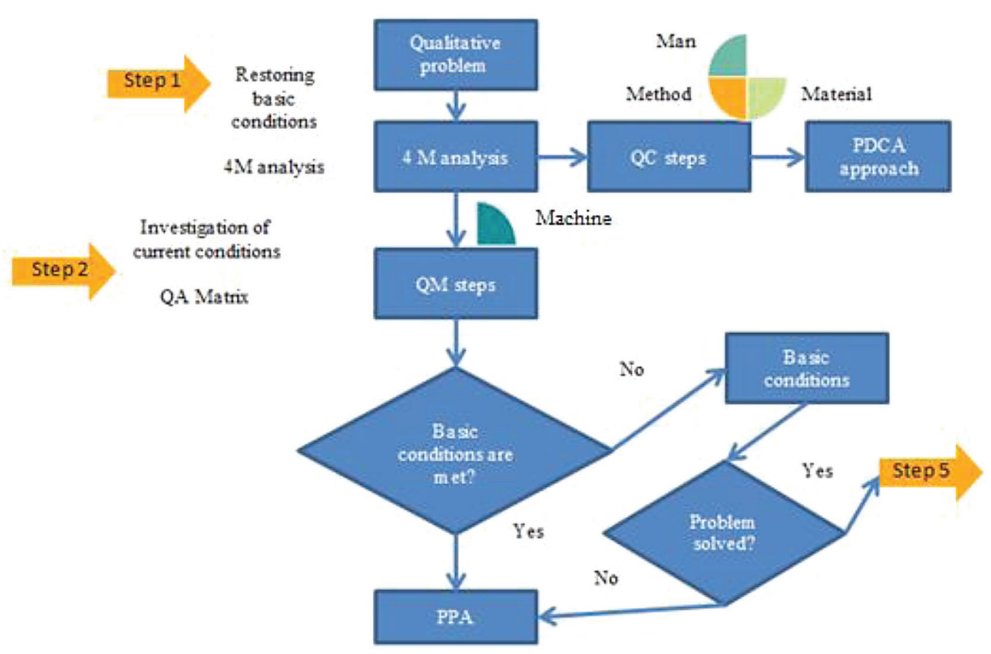

Fig. 4. The sequence of steps for checking and restoring the basic conditions 
Diagram of causes and consequences is also called Ishikawa diagram, or fishbone diagram. It identifies many possible causes for a specific consequence or problem and organizes ideas into six categories. It can be used by the $4 \mathrm{M}$ analysis to determine the relationships among all possible causes and consequences. An example of this diagram is shown in Figure 7.

Checklist comprises structured, prepared forms for data collection and analysis. This universal tool can be adapted for a variety of purposes. The forms are specifically designed for the collection of specific data for single record of characters (Figure 8).

Quality control charts are graphs used to study how the process changes over time. They are used for the data evaluations that show temporary changes and the relationships between variables (Figure 9).
Histogram is most commonly used chart to view a frequency distribution. It is used to visualize any changes in the measurement process during the time by quality control charts (Figure 10).

Pareto chart (Figure 11) shows on the column chart, which factors are more important. It is used to review the data and distribution of information across the defect. The Pareto principle shows that about $80 \%$ of consequences come from $20 \%$ of causes.

Scatter plot (Figure 12) shows a pair of graphs of numerical data with one variable on each axis to show the connections and relationships. It shows the data distribution. This is the estimation of the probability distribution of continuous variables. X-axis shows the number of intervals and Y-axis shows the frequency.

Flowchart uses graphical symbols to show the nature and flow of steps in the process (Figure 13).

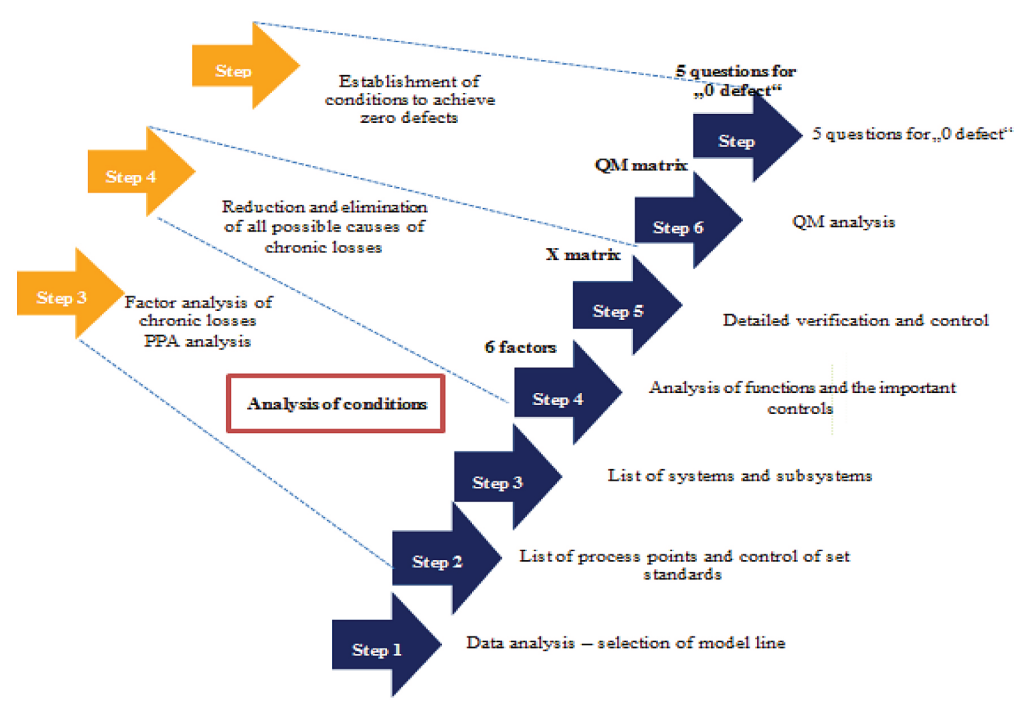

Fig. 5. PPA analysis -7 steps

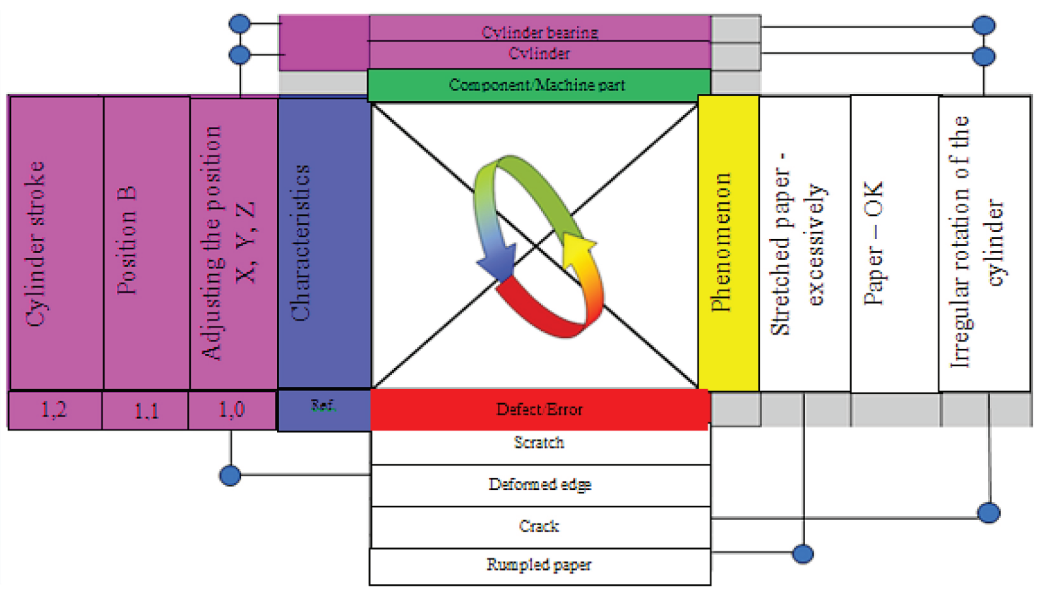

Fig. 6. X-matrix 
Table 1. QM matrix

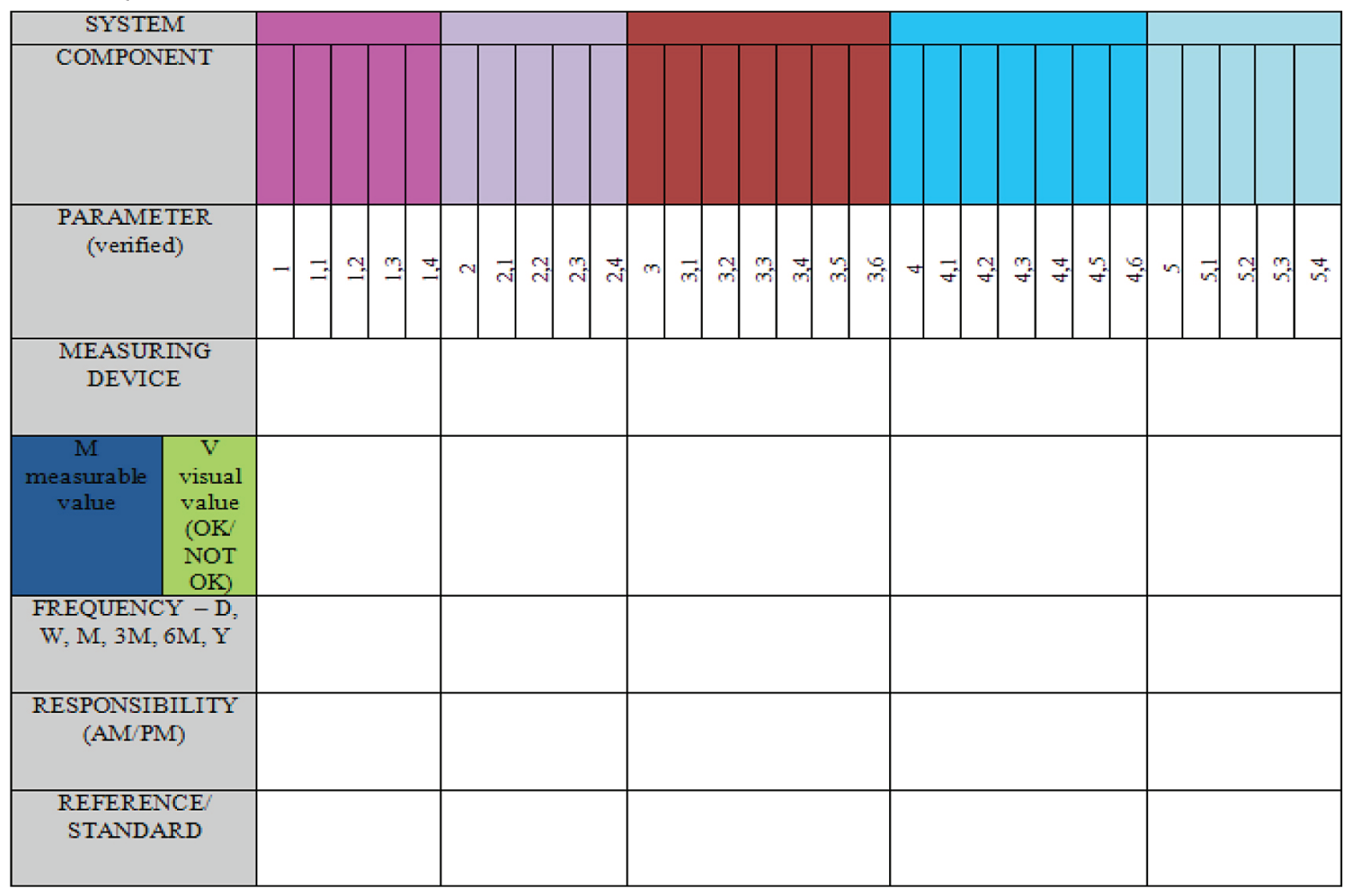

Table 2. Questions for the zero machine defects

\begin{tabular}{|c|c|c|c|c|c|c|}
\hline \multirow{2}{*}{\multicolumn{2}{|c|}{$\begin{array}{c}\text { Category: Machine } \\
\text { Questions }\end{array}$}} & & & & \multirow{2}{*}{ Before } & \multirow{2}{*}{ After } \\
\hline & & \multirow{2}{*}{$\begin{array}{c}1 \\
\begin{array}{c}\text { It is defined within } \\
\text { standard }\end{array}\end{array}$} & \multirow{2}{*}{$\begin{array}{c}3 \\
\begin{array}{c}\text { Simple verification } \\
\text { method }\end{array}\end{array}$} & \multirow{2}{*}{$\begin{array}{c}5 \\
\begin{array}{c}\text { Simple visual } \\
\text { inspection }\end{array}\end{array}$} & & \\
\hline 1. & $\begin{array}{l}\text { Are the conditions of } \\
\text { process setting clear? }\end{array}$ & & & & 1 & 3 \\
\hline 2. & $\begin{array}{l}\text { Are the basic } \\
\text { conditions easily set? }\end{array}$ & $\begin{array}{c}\text { Difficult setting, lack } \\
\text { of auxiliary reference } \\
\text { points }\end{array}$ & $\begin{array}{l}\text { Easy setup, reference } \\
\text { points presence }\end{array}$ & $\begin{array}{l}\text { Automatic } \\
\text { setting }\end{array}$ & 1 & 3 \\
\hline 3. & $\begin{array}{c}\text { Can the basic } \\
\text { conditions change? }\end{array}$ & $\begin{array}{l}\text { Normally during } \\
\text { normal production }\end{array}$ & Only during setup & $\begin{array}{c}\text { Only } \\
\text { exceptionally }\end{array}$ & 3 & 5 \\
\hline 4. & $\begin{array}{c}\text { Are the variable } \\
\text { conditions easily } \\
\text { verifiable? }\end{array}$ & $\begin{array}{l}\text { Difficult visually } \\
\text { control }\end{array}$ & $\begin{array}{c}\text { Standard measuring } \\
\text { system }\end{array}$ & $\begin{array}{l}\text { Continuous } \\
\text { monitoring }\end{array}$ & 1 & 5 \\
\hline 5. & $\begin{array}{l}\text { Is it easy these } \\
\text { conditions retum to } \\
\text { the basic status? }\end{array}$ & Maintenance & Trained operator & Automatically & 1 & 5 \\
\hline & & & & & $28 \%$ & $84 \%$ \\
\hline
\end{tabular}

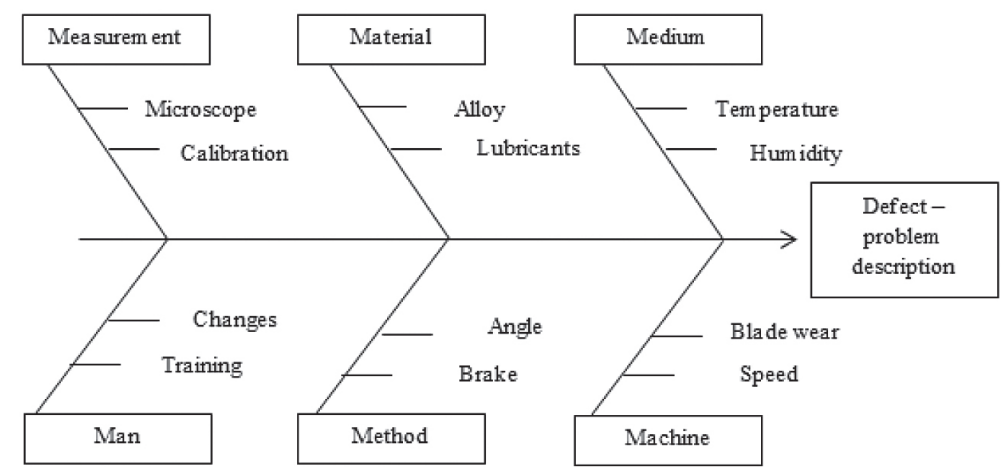

Fig. 7. Example of Ishikawa diagram 
Controller name:

Line:

Date of data collection:

\begin{tabular}{|c|c|c|c|c|c|c|c|c|}
\hline \multirow{2}{*}{$\begin{array}{l}\text { Types of defects / } \\
\text { event occurrence }\end{array}$} & \multicolumn{8}{|c|}{ Data } \\
\hline & Monday & Tuesday & Wednesday & Thursday & Friday & Saturday & Sunday & Sum \\
\hline $\begin{array}{l}\text { Rusty material } \\
\text { supplied }\end{array}$ & & 9 & 5 & 4 & 2 & & & 20 \\
\hline Offset weld & & & 3 & & 2 & & & 5 \\
\hline $\begin{array}{c}\text { Used incorrect } \\
\text { component }\end{array}$ & & & & & & & & 0 \\
\hline $\begin{array}{c}\text { Incorrect surface } \\
\text { treatment }\end{array}$ & & 3 & & & & 1 & & 4 \\
\hline Porous material & & & & & & & & 0 \\
\hline $\begin{array}{c}\text { Incorrect } \\
\text { parameters }\end{array}$ & & & 3 & & & 2 & & 5 \\
\hline Insoluble residues & & & & & & & & 0 \\
\hline Incorrect thread & 6 & & & 4 & & & & 10 \\
\hline $\begin{array}{c}\text { Cracks in the } \\
\text { material }\end{array}$ & & 2 & & & & 3 & & 5 \\
\hline Relieved seat & & & 5 & & & & & 5 \\
\hline Sum & 6 & 14 & 16 & 8 & 4 & 6 & 0 & \\
\hline
\end{tabular}

Fig. 8. Example of checklist
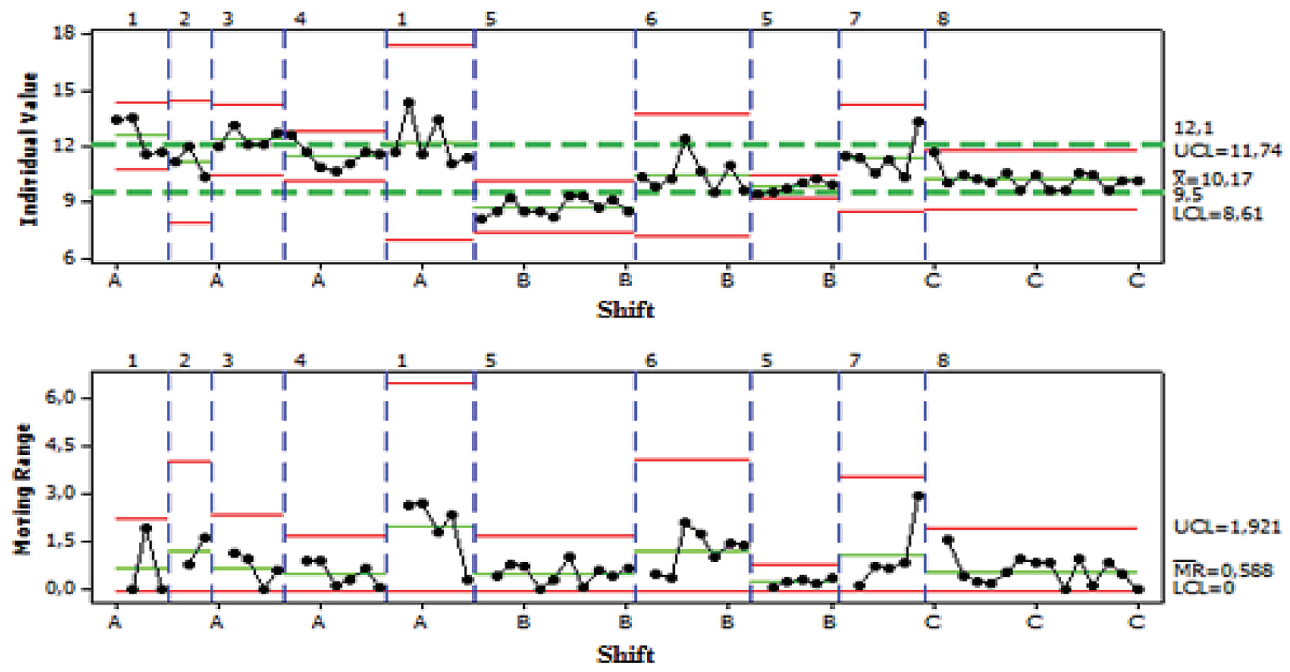

Fig. 9. Example of Quality control chart

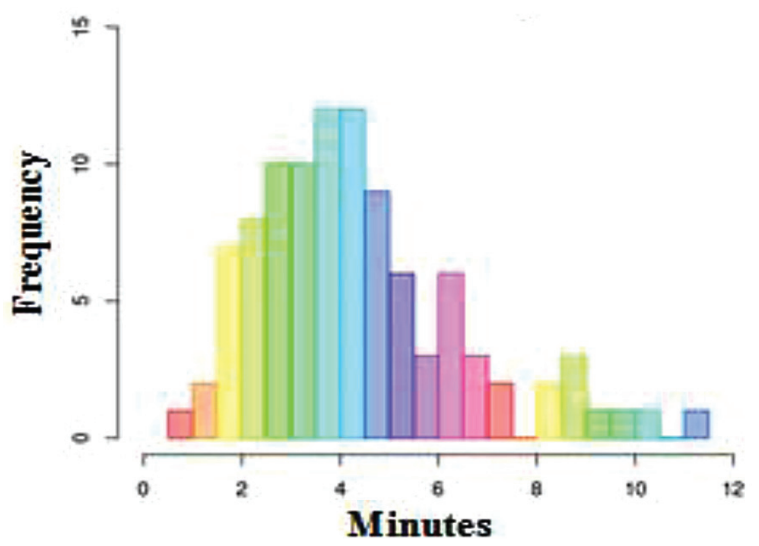

Fig. 10. Example of Histogram 


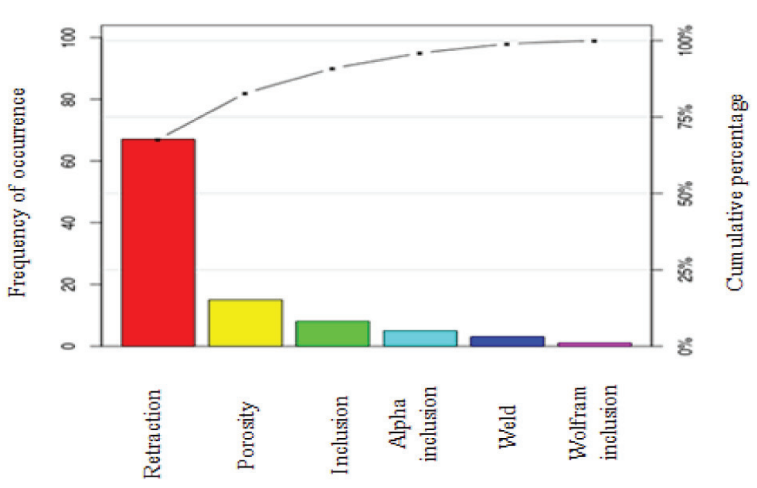

Fig. 11. Example of Pareto chart

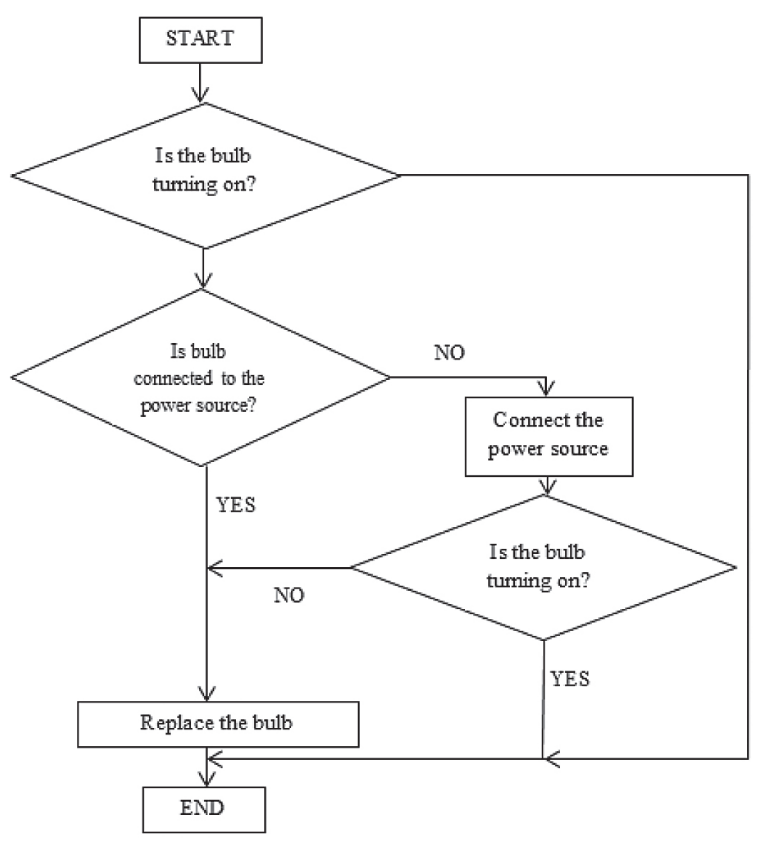

Fig. 13. Example of Flowchart

\section{CONCLUSIONS}

In the article, the authors focused on the application of Quality control steps in the selected global company. The Quality control pillar constituted a basis, on which the whole evaluation of quality in the global companies was built. Quality control was applied to find possible errors in quality through $4 \mathrm{M}$ categories and the possibilities of error minimization were indicated.

The authors dealt with the application of quality maintenance in the company, taking the FMEA method and QA matrix as a basis. Subsequently, the possibilities of defects identification in production process through PPA analysis and QM matrix was investigated. Attention was drawn to the fact that quality assessment is currently necessary to implement in several stages, through the use of Quality tools.

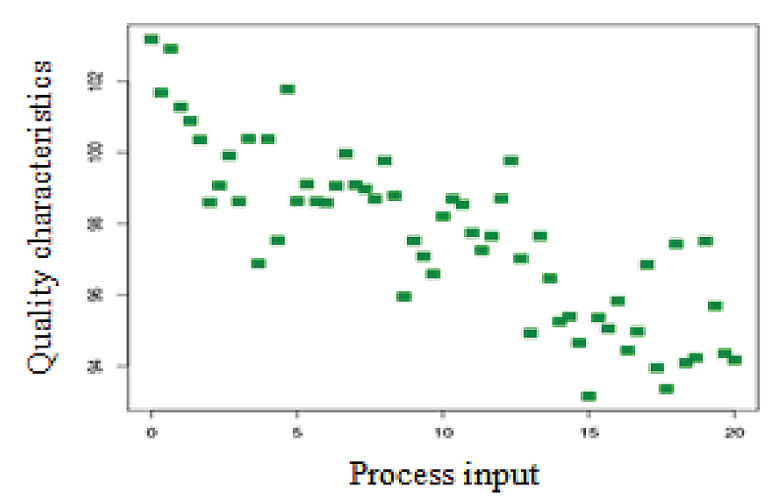

Fig. 12. Example of Scatter plot

From a practical point of view, the article can serve as a suitable inspirational tool for production companies, which have to evaluate quality in several stages, and from a theoretical point of view, it can contribute to the development of methodology for evaluation of the quality of production processes on the principles of World Class Manufacturing.

\section{Acknowledgements}

This work has been supported by the Scientific Grant Agency of the Ministry of Education of the Slovak Republic (KEGA 002TUKE-4/2020 and Project KEGA 032EU- 4/2020)

\section{REFERENCES}

1. Abele, T. (2006). Verfahren fúr das Technologie-Roadmapping zur Unterstútzung des strategischen Technologiemanagements. JostJetterVerlag, Heimsheim

2. Crosby, P. B. (2004). Quality Without Tears. McGraw-Hill Education. New York

3. Fabian, S., Straka, L. (2008). Operation of production systems. Edition of scientific and technical literature, FVT TU of Košice established in Prešov, Prešov. 252

4. Feigenbaum, A. V. (1956). Total Quality Control. Harvard business Review. 93 - 101

5. Hejazi, T. H., Seyyed-Esfahani,M.; Antony, J. (2017). A new methodology based on multistage stochastic programming for quality chain design problem. International Journal of Industrial Engineering: Theory, Applications and Practice. 24(1), 12-31

6. Imai, M. (1992). Kaizen - DerSchlüssel zum Erfolg der Japaner im Wettbeverb. Müller Herbig, München 
7. Juran, J. M. (1989). Juran on Leadership For Quality: An Executive Handbook. New York

8. Kovac, J. (2006). Designing of production processes and systems. TUKE, Kosice

9. Maskell, H. B. (1991). Performance Measurement for World Cass Manufacturing. Taylor \& Francis Inc., London

10. Mitra, A. (2008). Fundamentals of quality control and improvement. 3rd. ed. A John Wiley \& Sons, Inc., Publication.

11. Murata, K., Katayam, H. (2009). An evaluation of factory performance utilized KPI/KAI with data envelopment analysis. Journal of the Operations Research Society of Japan. 52(2), 204-220.

12. O'Brien, P. E. (1989). Construction Inspection Handbook - Quality Assurance/Quality Control. Springer. New York.

13. Oliver, N. et al. (1994). World class manufacturing: Further evidence in the lean production debate, British Journal of Management 5, $53-63$, doi.org/10.1111/j.1467-8551.1994.tb00130.x

14. Schoenberger, R. (1988). World class manufacturing, The lessons of simplicity applied, Free Press, New York

15. Sebestova, E. (2016). Application of innovative techniques in the production using WCM concept. Diploma work. SjF TU Kosice
16. Shirose, K. (1996). TPM New Implementation Program in Fabrication and Assembly Industries. Productivity Press, Portland, Oregon

17. Straka, L. (2005). New Trends in Technology System Operation, Proceedings of the 7 th conference with international participation in Prešov, 385-388

18. Sutaj-Estok, A., Liberko, I., Sirkova, M. (2012). Process management in relation to the systems thinking. Management 2012: research management and business in the light of practical needs, 214-218

19. Szwejczewski, M. (2012). Learning from World Class Manufacturers. Palgrave Macmillan, Poland

20. Tej, J. et al. (2014). Management simulation exercises - Insight into their use in the educational process. 2014 IEEE 12th IEEE International Conference on Emerging eLearning Technologies and Applications (ICETA), Stary Smokovec, 29-34

21. Villareal, B., Garza, F.; Rosas, I.; Garcia, D. (2012). An introduction to distribution operational efficiency. International Journal of Industrial Engineering: Theory, Applications and Practice. 19(7), 278-288

22. Wimalachandra, D. Ch., Frank, B., Enkawa, T. (2014). Strategic openness in quality control: adjusting NPD strategic orientation to optimize product quality. International Journal of Industrial Engineering: Theory, Applications and Practice. 21(6), 348-359 